\title{
Classification of pain following spinal cord injury
}

\author{
PJ Siddall, DA Taylor and MJ Cousins
}

Pain Management and Research Centre, University of Sydney, Royal North Shore Hospital, St Leonards, NSW, Australia, 2065

\begin{abstract}
Pain continues to be a significant management problem in people with spinal cord injuries. Despite this there is little consensus regarding the nature, terminology and definitions of the various types of pain that occur following spinal cord injury. This has led to large variations in the reported incidence and prevalence of pain following spinal cord injury. Treatment studies have been hampered by inconsistent and inaccurate identification of pain types. We believe that both research and management would benefit from an agreed upon classification system which accurately and reliably identifies the types of pain that occur following spinal cord injury. We have reviewed the literature on the classification of pain following spinal cord injury and have developed a classification system which adopts the strengths of previous systems and attempts to avoid the weaknesses inherent in others. Our proposed classification system of pain following spinal cord injury includes four major divisions: musculoskeletal, visceral, neuropathic and other types of pain. We have divided neuropathic pain on the basis of region into two subdivisions: neuropathic at level and neuropathic below level pain. We have further divided neuropathic at level pain into two categories: radicular and central, to indicate the presumed site of the lesion responsible for pain generation. We believe that our proposed classification system is comprehensive, simple and readily applicable in the clinical and research situation. It is our hope that this proposed classification will contribute to the eventual development of a universal system for the classification of pain following spinal cord injury.
\end{abstract}

Keywords: spinal cord injuries; pain; classification

\section{Introduction}

Since the early part of this century, reports have described the severe pain that can follow spinal cord injury $(\mathrm{SCI}) .^{1-17}$ In a recent review of the literature, it was reported that between $34 \%$ and $94 \%$ of patients from a group of 10 studies over the last 40 years experienced pain following SCI. ${ }^{18}$ In one third of these people the pain was described as severe. Although loss of function is often considered to be the most significant consequence of SCI, pain itself has a direct bearing on the ability or inability of the spinally injured person to regain his or her optimal level of activity. Results from a postal survey in Britain indicated that 98 people out of a total of 885 who replied stated that it was pain rather than loss of function that stopped them working. ${ }^{19}$ The impact of pain following SCI is also demonstrated by a study which reported that $37 \%$ of higher level SCI patients with pain and $23 \%$ of lower level SCI patients with pain would, if they had the chance, trade pain relief for loss of bladder, bowel or sexual function. $^{20}$

In recent years, significant advances have been made

Correspondence: PJ Siddall, MB, BS, Ph.D. in the understanding and management of pain. With these advances has come a greater precision in identifying and classifying types of pain. However, SCI pain has remained a comparatively neglected area. A comprehensive taxonomy of pain conditions was published recently by the International Association for the Study of Pain (IASP). ${ }^{21}$ However, no attempt was made in the taxonomy to define or categorise the various types of pain that occur following SCI. Out of more than 2400 articles that have been published in the journal Pain over the last 20 years, only 19 were specifically related to SCI pain. Similarly, of nearly 1700 articles published in the journal Paraplegia in the last 30 years, only 16 were specifically related to the problem of SCI pain.

Previous studies that have investigated or described the problem of pain following SCI have identified the existence of several types of pain based on descriptors and other features. ${ }^{1-17}$ However, there is little consensus regarding the classification, terminology and definitions of types of pain that occur following SCI, a fact that has been noted by others. $4,13,15,17,18,22-24$ The wide variation in the prevalence of SCI pain reported in the literature is partly a consequence of this lack of consensus. ${ }^{18}$ The 
variation may also be due to methodological issues of data collection such as time following injury, or the way in which data have been collected.

A standard classification system of SCI pain is extremely important in clinical research and treatment. SCI treatment studies rely on descriptors to indicate pain type, ${ }^{25}$ or use terms that are ambiguous and which therefore make it difficult to interpret their findings. ${ }^{26,27}$ Some SCI studies do use classification systems to indicate a particular type of pain, but there is little consistency of terminology. ${ }^{28}$ Communication amongst clinicians involved in treatment is also hampered by this lack of consistency.

The need for a classification system is also apparent in basic research. The focus in basic studies has been on an understanding of the mechanisms responsible for the development of pain following SCI. ${ }^{29-35}$ The question of mechanisms is of fundamental importance in the design of a classification system. Several mechanisms have been proposed to account for pain and other sensory disturbances following SCI. These include the concept of a "neuromatrix,36,37 or "pattern generating mechanism', activation of alternative pathways, ${ }^{38}$ abnormal activity of spinal $^{29}$ or supraspinal $^{39}$ neurons, or a disruption of the normal descending spinal inhibitory influences. ${ }^{40}$ The focus of this paper is not on the mechanisms of SCI pain. However, treatment is more likely to be successful if the underlying mechanisms are accurately identified.

There remains a need, therefore, for a comprehensive, reliable and easy to use classification system of SCI pain. The lack of a standard classification system has ramifications for basic and clinical research and for treatment. In addition, the differences in terminology prevent effective communication about SCI pain within and across disciplines. We believe that these issues must be addressed if advances are to be made in the understanding and management of SCI pain.

The aim of this paper, consequently, is to propose a classification system of pain following SCI and to argue for the adoption of a classification system that is accepted and agreed upon by workers in this field. We shall first discuss previous classification systems and their strengths and weaknesses. We shall then propose a new classification system that draws on the strengths of other systems and attempts to resolve their problems.

\section{Previous classification systems}

Previous classification systems have generally been based on criteria which fall into two main groups: classification by location or region of pain (eg, above lesion, below lesion), or classification by source of pain or presumed site of pathology (eg, musculoskeletal, visceral, root). Some classification systems also include descriptors (eg, burning, diffuse, dysaesthetic, late, etc.). Unfortunately, most systems rely on a combination of these criteria. A number of problems inherent in these classification systems are discussed in more detail below.

\section{Classification by region of pain}

Classification by location or region of pain has been used by several authors and provides a simple framework for classification. Riddoch ${ }^{1}$ classified pain as local and remote, Michaelis ${ }^{6}$ classified pain as above, at and below lesion level and Maury ${ }^{41}$ classified pain as sublesional, lesional and supra-lesional. While classification by location is simple and logically appealing, use of location to classify pain is problematic. For example, pain arising from both musculoskeletal and nervous structures can occur at the level of the lesion. Pain arising from both spinal cord pathology or visceral structures can occur below the level of the lesion. Therefore, further definition (eg musculoskeletal, visceral) is required to identify accurately the type of pain that is being described. When this is done, classification by region of pain loses its appeal.

\section{Classification by source of pain or pathology}

In an attempt to provide greater accuracy, other authors have classified SCI pain according to the presumed site of origin or the source of the pain rather than the site of pain where the pain is perceived. Terms used in these classification systems include: musculoskeletal, visceral, root, sympathetic and psychic, ${ }^{4}$ root, visceral and central, ${ }^{7}$ neurologic, central or psychologic, ${ }^{10}$ segmental nerve, spinal cord, visceral, mechanical and psychogenic, ${ }^{11}$ musculoskeletal, radicular, border reaction and central ${ }^{12}$ and central, root, visceral and musculoskeletal. ${ }^{18}$

Although classification by source of pathology provides greater accuracy, there is a problem associated with the use of these systems. Ambiguity arises when terms which are based on assumptions about the source of the pain, and which therefore imply mechanisms (eg, root or radicular), are used with no evidence for these assumptions. Reviewers agree that the pathophysiology of SCI neuropathic pain is only partly understood. Therefore, to use terms which assume pathophysiology, which is unproven or unknown, only leads to confusion and misunderstanding.

For example, the type of pain that is dermatomal, burning, aching or sharp, sometimes with hyperaesthesia at the level of the injury, is often labelled as 'root' or 'radicular' pain. Although these descriptors are consistent with the pain that occurs with nerve root pathology, it is not certain that nerve root damage is the underlying cause of 'radicular' pain following SCI Recent evidence from basic studies indicates that dermatomal hypersensitivity or allodynia may be present in the absence of nerve root damage and may be due to changes within the spinal cord itself. ${ }^{34}$ As Burke and Woodward ${ }^{5}$ note, pain may often be classified as 'root pain' in the absence of any demonstrable pathology that may be affecting the nerve root. Therefore, while this typical 'radicular' pattern of pain with shooting, stabbing, burning pain with or without hyperaesthesia may be due to nerve 
root damage, this cannot be assumed on description alone. Using the words 'root' or 'radicular', which is presumptive of mechanism, purely on the basis of pain descriptors, is, therefore, difficult to justify.

\section{Mixed classification systems}

While some authors attempt to classify pain according to one criteria, the majority of authors use systems which classify pain using several criteria. These systems use a mix of pain location and site of origin, eg below lesion level, root and visceral, ${ }^{3}$ site of trauma, radicular, below injury level ${ }^{8}$ and segmental, radicular, phantom, visceral. ${ }^{16}$ Some authors also use pain descriptors such as 'dysaesthetic'11,13,15 or 'diffuse burning' and 'early burning', 5 either alone or in combination with other criteria. Several authors use the word 'phantom' to describe the pain which occurs in an area of sensory loss. ${ }^{4,16}$ It is recognised that it is difficult to produce a comprehensive classification system based on a single criterion. However, mixed classification systems not only have the problems associated with the use of pain location or pathology as criteria, but also introduce problems because of the different discriminating criteria that are used within the same classification system.

The introduction of descriptors into a classification system introduces further problems. Different types of pain may have the same features. For example 'burning, tingling and aching' could equally describe 'root' pain as defined by some authors ${ }^{2,4,8,12,18}$ or diffuse pain below the level of the lesion as described by others. ${ }^{12,13,15,18}$ Burning, tingling and aching could also refer to segmental pain 1,16 or to the pain associated with syringomyelia. ${ }^{16}$

The descriptors used to classify SCI pain are also often imprecise or confusing. For example, dysaesthesia means 'an unpleasant abnormal sensation', ${ }^{21}$ and to include this descriptor in a classification of pain types therefore adds little to identify a particular type or category of pain. Burning pain has been termed 'sympathetic' by one author ${ }^{4}$ and yet this pain may not be related to sympathetic nervous system function or dysfunction.

\section{General problems}

Each of these classification systems presents problems specific to the criteria used. However, there are also general problems that arise from previous classification systems. The first problem is that there is little or no consensus regarding the number, types or terminology of pain following SCI. Whilst there is broad agreement as to the categories that may present, eg mechanical or musculoskeletal, visceral, radicular and dysaesthetic or central, some authors include categories such as psychologic $4,10,11$ that other authors leave out or reject. ${ }^{15,18,23,42}$ Other authors include pains such as headache or reflex sympathetic dystrophy, which are more indirectly related to SCI. ${ }^{5,6,18}$
The problems described above are illustrated in a recent comprehensive review of SCI pain. ${ }^{17}$ Having reviewed the various classification systems which have been used, one particular classification system ${ }^{11}$ is endorsed as 'highly practical and intellectually satisfying'. While we recognise that this classification system does attempt to bring together criteria into a coherent system, the system does not include end-zone, border reaction or segmental pain ${ }^{5,12,16}$ which are included in other systems. Furthermore, this system includes psychogenic pain which, while included by some previous authors, ${ }^{4,10}$ is open to question and disputed by others. ${ }^{15,23}$ Finally, this system is based on assumptions about neurophysiological mechanisms which are hard to justify when these mechanisms are still largely unknown. Therefore the classification system, which certainly is 'highly practical and intellectually satisfying', nevertheless fails to address many of the problems that we have identified.

\section{A proposed classification system}

Different classification models are applicable in any attempt to define and categorise. As described by Turk and Rudy, ${ }^{43}$ the classification of diseases (and therefore of pain) is usually based on a combination of characteristics that identify a specific problem. The characteristics used to identify different types of pain include descriptors, location, system, aetiology, mechanism or a combination of these. Consequently, one of the aims in designing a classification system is to clarify the specific characteristics that are most closely associated with a specific pain state. This will assist to identify and to classify the different types of SCI pain. However, to be readily useable, the classification system must be as simple as possible. The terms used need to be clearly defined or readily apparent to the user and need to be based on features that are identifiable or known.

We have identified several symptom/sign constellations which have been described by previous authors in an attempt to classify these into separate categories which can then be labelled. These constellations generally fall into five broad categories (Table 1).

The five categories are: 1. musculoskeletal; 2. visceral; 3. neuropathic pain at the level of the lesion (neuropathic I); 4. neuropathic pain below the level of the lesion (neuropathic II); and 5. other types of pain. It seems logical to assign pains to these five categories as it appears from reports that these pains are distinguishable in terms of descriptors and/or site. Presumably the categories also have different mechanisms. Several authors have mentioned other types of pain such as psychological or psychogenic, $4,10,11$ headache associated with dysreflexia, 'sympathetic', reflex sympathetic dystrophy, ${ }^{18}$ pain associated with spasticity $^{4}$ and compressive neuropathies. ${ }^{18}$ The question of the inclusion of psychological or psychogenic pain will be dealt with later but in our opinion 
Table 1 Summary of previous classification systems

\begin{tabular}{|c|c|c|c|c|c|}
\hline & Musculoskeletal & Visceral & Neuropathic (I) & Neuropathic (II) & Other \\
\hline Riddoch $^{1}$ & & & local segmental & remote & \\
\hline Davis $^{2}$ & & visceral & root & diffuse, burning & \\
\hline Pollock $^{3}$ & & visceral & root & below lesion & \\
\hline Kaplan ${ }^{4}$ & musculoskeletal & visceral & root & phantom & psychic, sympathetic \\
\hline Michaelis $^{6}$ & at level & & at level & below level & headache \\
\hline Burke $^{7}$ & & visceral & root & central & \\
\hline Davis $^{8}$ & trauma site & & radicular & below level & \\
\hline $\begin{array}{l}\text { Burke } \\
\text { and Woodward }\end{array}$ & early, chronic spinal & visceral & $\begin{array}{l}\text { early 'burning', } \\
\text { root, end-zone }\end{array}$ & diffuse 'burning' & headache \\
\hline Bedbrook $^{10}$ & & & neurologic & central & psychologic \\
\hline Donovan $^{11}$ & mechanical & visceral & segmental & central dysaesthetic & psychogenic \\
\hline Tunks $^{12}$ & musculoskeletal & & $\begin{array}{l}\text { radicular, border } \\
\text { reaction }\end{array}$ & central & syringomyelia \\
\hline Davidoff $^{13}$ & & & & dysaesthetic & \\
\hline Britell $^{15}$ & mechanical & & radicular & dysaesthetic & \\
\hline Bonica $^{18}$ & musculoskeletal & visceral & root & central & RSD, mononeuropathy \\
\hline Nashold $^{16}$ & & visceral & radicular, segmental & phantom & syringomyelia \\
\hline
\end{tabular}

psychological pain should not be included as a separate category. We therefore propose the following classification system (Table 2 ).

\section{Main pain types}

The first level of pain grouping proposed, i.e. Axis 1, (musculoskeletal, visceral and neuropathic, other) provides a classification that is based on a similar factor, i.e. system, and is readily identifiable in the clinical situation. The terms 'musculoskeletal, visceral and neuropathic' are also generally used to identify and classify pain problems.

\section{Musculoskeletal pain}

Musculoskeletal pain arises from damage or overuse in structures such as bones, ligaments, muscles, intervertebral discs and facet joints. Musculoskeletal pain also includes mechanical pain due to damage to spinal structures, eg the acute pain that occurs prior to spinal stabilising operations. Musculoskeletal pain can be identified by location (at or above lesion level in those with complete spinal cord lesions) and by pain features (dull, aching, worse with activities, eased by rest).

\section{Visceral pain}

Visceral pain can be identified by location (abdomen) and by pain features (dull, poorly localised, cramping, related to visceral function or pathology). If investigations fail to find evidence of visceral pathology, and if blockade of peripheral inputs from visceral structures fails to alleviate pain, then consideration must be given to classifying the pain as neuropathic rather than visceral.
Table 2 Proposed classification system

\begin{tabular}{|c|c|c|}
\hline $\begin{array}{l}\text { AXIS 1 } 1 \\
\text { (System) }\end{array}$ & $\begin{array}{l}\text { AXIS } 2 \\
\text { (Site) }\end{array}$ & $\begin{array}{l}\text { AXIS } 3 \\
\text { (Source) }\end{array}$ \\
\hline \multicolumn{3}{|c|}{$\begin{array}{l}\text { Musculoskeletal } \\
\text { Visceral }\end{array}$} \\
\hline Neuropathic & $\begin{array}{l}\text { at level* } \\
\text { below level }\end{array}$ & $\begin{array}{l}\text { radicular } \\
\text { central }\end{array}$ \\
\hline \multicolumn{3}{|c|}{$\begin{array}{l}\text { Other } \\
\text { (eg syringomyelia, complex regional pain } \\
\text { syndromes, overuse syndromes, headache } \\
\text { associated with dysreflexia compressive } \\
\text { mononeuropathies) }\end{array}$} \\
\hline
\end{tabular}

\section{Neuropathic pain}

'Neuropathic pain' is a generally accepted term which is used to describe pain that occurs following damage to the central or peripheral nervous system. ${ }^{21}$ Neuropathic pain can be identified by site (region of sensory disturbance) and by features (sharp, shooting, electric, burning, stabbing).

The main difficulty in any classification system of SCI pain occurs with any further classification of neuropathic pain. Clearly there is a need for further breakdown, as there are several pains that have been identified (root, central, end-zone, etc) that fall under the category of neuropathic pain. However, as we mentioned above, several problems occur when attempts are made to define different types of pain within the general neuropathic pain group.

We propose, therefore, that any further classification of neuropathic pain should be done on the basis of site of pain, ie Axis 2 (at level or below level). As 
mentioned previously, it is extremely difficult to distinguish types of neuropathic pain on the basis of descriptors or features. In addition, the mechanisms of neuropathic pain are as yet not understood. Site is easy to distinguish on clinical grounds and provides a simple method of further distinction which is readily and reliably determined. Furthermore, site provides useful information to describe clinically the type of pain that is present. People who have pain in a region of sensory disturbance with neuropathic features (burning, stabbing, electric, shooting) should therefore be classified as having neuropathic at level or neuropathic below level pain. While this may appear simplistic, it is hard to categorise any further than this without alluding to mechanisms which at this stage are largely unknown.

Neuropathic at level pain For the first type of neuropathic pain, we propose the term 'neuropathic at level pain'. Neuropathic at level pain can be further divided according to the source of pain, i.e. Axis 3 (radicular or central). However, this can only be done where there is definitive evidence which allows this division to be made. It is recognised that some patients with neuropathic pain at the level of the lesion will have pain of nerve root origin. Pain arising from nerve root damage may be suggested by neuropathic features (eg burning, stabbing, shooting, electric descriptors, presence of allodynia) with characteristics such as increased pain in relation to spinal movement. The pain may be due to direct damage to the nerve root during the initial injury or it may be secondary to spinal column instability and impingement by facet or disc material. In the past, pain that occurs at the level of the lesion and has features of nerve root pain in the absence of definitive evidence of nerve root damage has often been classified as radicular. However, pain with features which are suggestive of nerve root damage may occur in the absence of root damage and may be due to spinal rather than nerve root pathology. Therefore, the term 'radicular' to describe this type of pain should be used with caution.

It is also possible that neuropathic SCI pain in a segmental distribution at the level of injury is due to pathology within the spinal cord or other parts of the central nervous system. Some previous classification systems included this type of pain as a separate category and distinguished it from pain due to nerve root pathology. $1,5,12,16$ The only distinguishing feature of central pain appears to be that the pain is bilateral in distribution. ${ }^{1,5}$ We propose, therefore, that this type of pain be referred to as neuropathic at level central pain.

It is possible that use of the word 'central' may lead to some confusion. The IASP Classification of Chronic Pain defines central pain as 'regional pain caused by a primary lesion or dysfunction of the central nervous system' and the term 'central pain' is often used to describe a variety of syndromes associated with central nervous system lesions such as tumours, haemorrhage, ischaemia and trauma to the brain and spinal cord. In the context of SCI, central pain has often been used in the past to describe the diffuse neuropathic pain and dysaesthesiae that occur below the level of the lesion. We suggest that the use of the word 'central' to describe pain below the level of the lesion is misleading, as both neuropathic pain below, and at, the level of the lesion may be due to changes within the central nervous system. We believe that it is more useful to use the term "neuropathic at level central pain' to discriminate between neuropathic pain at the level of lesion which arises from changes in the central nervous system, including the spinal cord, in distinction to 'neuropathic at level radicular pain' which arises from pathology in the peripheral nervous system.

Therefore, pain which occurs at the level of spinal cord injury in a segmental pattern with neuropathic features may be termed either 'neuropathic at level radicular pain', ie pain due to nerve root pathology or 'neuropathic at level central pain', ie pain due to changes within the spinal cord or possibly supraspinal structures. While recognising that neuropathic at level radicular and central pains form separate entities, we propose that, unless there is definitive evidence of nerve root damage (eg imaging evidence of intervertebral foraminal compression), no further classification can be made beyond neuropathic at level pain. At present, it is not possible to provide definitive evidence of neuropathic at level central pain. It would be anticipated that further advances will allow identification of the source and mechanism of pains that fall into the category of neuropathic at level central pain. Until this is done we believe that pain which is described as burning, tingling, sharp, aching, shooting in a dermatomal distribution at the level of the lesion with or without hyperaesthesia should be classified as neuropathic at level pain. 'At level' should include two segments above and below the level of SCI because input from several segments may be disrupted or disturbed following injury at any particular level. It should also be noted that pain following cauda equina lesions that is neuropathic in nature must by definition be neuropathic at level radicular pain.

Neuropathic below level pain For the second type of neuropathic pain, we propose the term 'neuropathic below level pain'. 'Below level' is a term that has been used by others, ${ }^{6,8}$ is easy to identify and is consistent with the terminology used to identify neuropathic at level pain. Terms used by others either have a similar meaning to below level (eg remote, below lesion) or use descriptors that can be confused with other types of neuropathic pain (eg dysaesthetic, burning). 'Central pain' is another term that has been used. This is also misleading because, as discussed above, neuropathic at level pain may also have central mechanisms. 'Deafferentation pain' has also been used but fails to distinguish between the two types of neuropathic pain, both of which are the result of deafferentation. 
We propose that neuropathic below level pain should include pain that is described by the words burning, tingling, aching, shooting, stabbing. However, in distinction to neuropathic at level pain, neuropathic below level pain is present at least three segments below the level of injury and is more likely to be diffuse.

Two criticisms could be made of our suggested use of the term 'neuropathic'. First, it could be argued that the term is not consistent with the use of the terms 'musculoskeletal' or 'visceral' which indicate systems rather than pathology of systems. Secondly, it could be argued that radicular pain is strictly 'neurogenic' rather than 'neuropathic'.

With regard to the first criticism, we agree that it would be more consistent to use a term such as 'neurological' rather than 'neuropathic'. However, it is common practice to refer to pain arising from the nervous system as neuropathic rather than neurological. To use a term such as 'neurological' would probably cause confusion in introducing a term which is not in common usage.

With regard to the second criticism, it could be argued that neuropathic at level radicular pain is neurogenic rather than neuropathic pain since the IASP Classification of Chronic Pain distinguishes these two on the basis of neurogenic pain being due to a 'transitory perturbation of the nervous system'. ${ }^{21}$ While we agree with this, we believe that it is better to include radicular within the classification of neuropathic pain for three reasons: first, neurogenic pain is a subtype of neuropathic pain and can be included within this classification; secondly, it is difficult to distinguish neuropathic at level radicular pain from neuropathic at level central pain on the basis of descriptors. Therefore it is only with the passage of time, or with appropriate intervention or investigation that it will become clear whether the pain is radicular and therefore neurogenic in nature; and thirdly, it is our aim to produce a classification system which is simple to use.

\section{Other pain types}

The last category in our proposed classification system includes other specific types of pain which several authors mention but are not included in the categories listed above. These types of pain are specific pains that are a consequence of SCI. These include such pains as syringomyelia, headache associated with dysreflexia, compressive mononeuropathies and reflex sympathetic dystrophy. It should also be noted that the recent IASP Classification of Chronic Pain has replaced the terms 'reflex sympathetic dystrophy and causalgia' with the terms 'complex regional pain syndrome, types I and II' respectively. ${ }^{21}$ This terminology should be used instead of other terms such as 'shoulder-hand syndrome', which are often used to describe complex regional pain syndrome, type I.

Regarding the issue of psychological pain, several authors include this category when describing pain categories following SCI, ${ }^{4,10,11}$ while other authors specifically exclude it. ${ }^{15,18,23,42}$ We agree with the views of Britell and Mariano ${ }^{15}$ that inclusion of psychological pain as a separate category implies a dualistic approach to pain which is inconsistent with current thinking. There is no doubt that psychological issues have tremendous importance in the experience and expression of pain. ${ }^{44}$ It should be recognised that psychological factors will interact with physiological factors to affect any of the pains described above.

Some people have sensations following spinal cord injury which, while annoying or unpleasant, are not regarded as 'pain'. If asked to rate their pain on a numerical scale these people assign a value of ' 0 ', corresponding to no pain at all. We suggest that such sensations should not be included in a SCI pain classification. Similarly, 'phantom' phenomena or sensations which are not painful should also not be classified as pain. However, pain and other sensations following SCI may have similar mechanisms and therefore it may be useful to note the presence of these sensations when classifying pain.

\section{Conclusions}

We believe that there is a need for an agreed upon classification system of SCI pain. There has been little consensus regarding the number of types, terminology or definitions of pain following SCI. A systematic, reliable and useable system will result in improved communication which will ultimately benefit both research and treatment.

The system that we have proposed divides pain into four main categories: musculoskeletal, visceral, neuropathic and other. Neuropathic pain is further divided into neuropathic at level and neuropathic below level pain. Neuropathic at level pain is divided into neuropathic at level radicular and neuropathic at level central pain.

Our classification system is meant to be simple and useable rather than definitive, with the aim of achieving consensus amongst those working in the field of SCI. We recognise that much more detail could be added. The IASP Classification of Chronic Pain ${ }^{21}$ provides a detailed classification of musculoskeletal and radicular pain following injury to the spinal column. If desired, further classification which identifies the spinal level of injury and structures believed to be involved in the generation of pain could occur using the IASP system.

Our classification system is comprehensive yet simple and is readily applicable in the clinical situation. It also provides for further levels of classification as understanding of SCI pain progresses. It is our hope that our ideas will contribute to the eventual development of a universal system for the classification of pain following spinal cord injury. 


\section{Acknowledgements}

This work was supported by the Motor Accidents Authority, NSW, WorkCover's Injury Prevention, Education and Research Grants Scheme, the Spinal Research Fund, Royal North Shore Hospital, Sydney, Australia and the National Health \& Medical Research Council, Australia. We are grateful to Prof. John Loeser, University of Washington, Seattle, Prof. Ronald Melzack, McGill University, Montreal, Dr Sue Rutkowski and Dr James Middleton of the Spinal Injuries Unit, Royal North Shore Hospital and Joan McClelland, RN and Kathy Gustafson, RN from our own Department for their helpful comments in preparing this manuscript.

\section{References}

1 Riddoch G. The clinical features of central pain. Lancet 1938; 234: $1150-1156$.

2 Davis L, Martin J. Studies upon spinal cord injuries. J Neurosurg 1947; 4: 483-491.

3 Pollock LJ et al. Pain below the level of injury of the spinal cord. Arch Neurol Psychiatry 1951; 65: 319-322.

4 Kaplan LI, Grynbaum BB, Lloyd KE, Rusk HA. Pain and spasticity in patients with spinal cord dysfunction. JAMA 1962 ; 182: $918-925$.

5 Burke DC, Woodward JM. Pain and phantom sensation in spinal paralysis. In: Vinken PJ, Bruyn GW (eds). Handbook of Clinical Neurology. Elsevier: New York 1976, pp 489-499.

6 Michaelis LS. The problem of pain in paraplegia and tetraplegia. Bull NY Acad Med 1970; 46: 88-96.

7 Burke DC. Pain in paraplegia. Paraplegia 1973; 10: 297-313.

8 Davis R. Pain and suffering following spinal cord injury. Clin Orthop 1975; 112: $76-80$.

9 Melzack R, Loeser JD. Phantom body pain in paraplegics: evidence for a central 'pattern generating mechanism' for pain. Pain 1978; 4: 195-210.

10 Bedbrook GM. Pain and phantom sensation. In: Bedbrook GM (ed). The Care and Management of Spinal Cord Injuries. SpringerVerlag: New York 1981, pp 224-229.

11 Donovan WH, Dimitrijevic MR, Dahm L, Dimitrijevic M. Neurophysiological approaches to chronic pain following spinal cord injury. Paraplegia 1982; 20: $135-146$.

12 Tunks E. Pain in spinal cord injured patients. In: Bloch RF, Basbaum M (eds). Management of Spinal Cord Injuries. Williams and Wilkins: Baltimore 1986, pp 180-211.

13 Davidoff $\mathrm{G}$ et al. Function-limiting dysesthetic pain syndrome among traumatic spinal cord injury patients: a cross-sectional study. Pain 1987; 29: $39-48$

14 Beric A, Dimitrijevic MR, Lindblom U. Central dysesthesia syndrome in spinal cord injury patients. Pain 1988; 34: $109-116$

15 Britell CW, Mariano AJ. Chronic pain in spinal cord injury. Physical Medicine and Rehabilitation: State of the Art Reviews 1991; 5: $71-82$.

16 Nashold BS. Paraplegia and pain. In: Nashold BS, OvelmenLevitt J (eds). Deafferentation Pain Syndromes: Pathophysiology and Treatment. Raven Press: New York 1991, pp 301-319.

17 Roth EJ. Pain in spinal cord injury. In: Yarkony GM (ed). Spinal Cord Injury: Medical and Rehabilitation Management. Aspen Publishers: Gaithersburg, Maryland 1994, pp 141-158.

18 Bonica JJ. Introduction: semantic, epidemiologic, and educational issues. In: Casey KL (ed) Pain and Central Nervous System Disease: The Central Pain Syndromes. Raven Press: New York 1991, pp $13-29$.

19 Rose M, Robinson JE, Ells P, Cole JD. Pain following spinal cord injury: results from a postal survey. Pain 1988; 34: $101-102$.

20 Nepomuceno C et al. Pain in patients with spinal cord injury. Arch Phys Med Rehabil 1979; 60: 605-609.
21 Merskey $\mathrm{H}$, Bogduk $\mathrm{N}$ (ed). Classification of chronic pain: descriptions of chronic pain syndromes and definitions of pain terms. 2nd ed. Seattle: IASP Press; 1994.

22 Bedbrook GM. Pain in paraplegia and tetraplegia. In: Bedbrook GM (ed). Lifetime Care of the Paraplegic Patient. ChurchillLivingstone: Edinburgh 1985, pp 245-256.

23 Mariano AJ. Chronic pain and spinal cord injury. Clin J Pain 1992; 8: $87-92$.

24 Siddall PJ, Taylor DA, Cousins MJ. Pain associated with spinal cord injury. Curr Opin Neurol 1995; 8: $447-450$.

25 Backonja M, Gombar KA. Response of central pain syndromes to intravenous lidocaine. J Pain Symptom Manage 1992; 7: 172 178.

26 Glynn CJ et al. Role of spinal noradrenergic system in transmission of pain in patients with spinal cord injury. Lancet 1986; ii: $1249-1250$.

27 Herman RM, D'Luzansky SC, Ippolito R. Intrathecal baclofen suppresses central pain in patients with spinal lesions: a pilot study. Clin J Pain 1992; 8: 338 - 345.

28 Sandford PR, Lindblom LB, Haddox JD. Amitriptyline and carbamazepine in the treatment of dysesthetic pain in spinal cord injury. Arch Phys Med Rehabil 1992; 73: 300-301.

29 Loeser JD, Ward AA, White LE. Chronic deafferentation of human spinal cord neurons. J Neurosurg 1968; 29: 48 - 50 .

30 Levitt M, Levitt JH. The deafferentation syndrome in monkeys: dysaesthesias of spinal origin. Pain 1981; 10: 129-147.

31 Levitt $\mathrm{M}$. The bilaterally symmetrical deafferentation syndrome in macaques after bilateral spinal lesions: evidence for dysesthesias resulting from brain foci and considerations of spinal pain pathways. Pain 1983; 16: $167-184$.

32 Lenz FA et al. Abnormal single-unit activity recorded in the somatosensory thalamus of a quadriplegic patient with central pain. Pain 1987; 31: 225-236.

33 Hao JX et al. Allodynia-like effects in rat after ischaemic spinal cord injury photochemically induced by laser irradiation. Pain 1991; 45: 175-185.

$34 \mathrm{Xu} \mathrm{XJ}$ et al. Chronic pain-related behaviours in spinally injured rats-evidence for functional alterations of the endogenous cholecystokinin and opioid systems. Pain 1994; 56: $271-277$.

35 Siddall PJ, Xu CL, Cousins MJ. Allodynia following traumatic spinal cord injury in the rat. Neuroreport 1995; 6: $1241-1244$.

36 Melzack R. The John J. Bonica Distinguished Lecture: The gate control theory 25 years later: new perspectives in phantom limb pain. In: Bond M, Charlton E, Woolf CJ (eds). Pain Research and Clinical Management, Vol. 4, Proceedings of the VIth World Congress on Pain. Elsevier: Amsterdam 1991, pp 9-21.

37 Melzack R. Phantom limbs. Sci Am 1992; 266: 120-126.

38 Craig AD. Supraspinal pathways and mechanisms relevant to central pain. In: Casey KL (ed). Pain and Central Nervous System Disease: The Central Pain Syndromes. Raven Press: New York 1991, pp $157-170$.

39 Lenz FA. The thalamus and central pain syndromes: human and animal studies. In: Casey KL (ed). Pain and Central Nervous System Disease: The Central Pain Syndromes. Raven Press: New York 1991, pp $171-182$.

40 Zimmerman M. Central nervous mechanisms modulating painrelated information: do they become deficient after lesions of the peripheral or central nervous system? In: Casey KL (ed). Pain and Central Nervous System Disease: The Central Pain Syndromes. Raven Press: New York 1991, pp 183-199.

41 Maury M. About pain and its treatment in paraplegics. Parapalegia 1978; 15: 349 - 352

42 Siddall PJ, Cousins MJ. Post spinal cord injury pain: mechanisms and treatment options. In: Stanley TH, Ashburn MA (eds). Anesthesiology and Pain Management. Kluwer Academic: Amsterdam 1994, pp 237-251.

43 Turk DC, Rudy TE. Classification logic and strategies in chronic pain. In: Turk DC, Melzack R (eds). Handbook of Pain Assessment. Guilford: New York 1992, pp 409-428.

44 Craig KD. Emotional aspects of pain. In: Wall PD, Melzack R (eds). Textbook of Pain 3rd edn. Churchill Livingstone: Edinburgh 1994, pp $261-274$. 